\title{
Prevalence, awareness, treatment, control and socio demographic determinants of hypertension in Malaysian adults
}

\author{
Suraya Abdul-Razak 1,2,6*, Aqil Mohammad Daher ${ }^{3}$, Anis Safura Ramli 1,2,4,6, Farnaza Ariffin 1,4,6, \\ Md Yasin Mazapuspavina ${ }^{1,4,6}$, Krishnapillai S. Ambigga ${ }^{3}$, Maizatullifah Miskan ${ }^{3}$, Hasidah Abdul-Hamid ${ }^{1,4,6}$, \\ Nafiza Mat-Nasir ${ }^{1,4,6}$, Mohamed Noor Khan Nor-Ashikin ${ }^{1,4}$, Kien Keat Ng ${ }^{3}$, Hapizah Nawawi ${ }^{1,2}$, \\ Khalid Yusoff ${ }^{4,5}$ and for the REDISCOVER Investigators
}

\begin{abstract}
Background: Hypertension is the leading cardiovascular risk factor globally as well as in Malaysia. This study aimed to estimate the prevalence, awareness, treatment, control and the socio demographic determinants of hypertension among Malaysian adults.

Method: The analytic sample consisted of 11,288 adults aged $\geq 30$ years recruited at baseline in 2007-2011 from the REDISCOVER Study which is an ongoing, prospective cohort study involving 18 urban and 22 rural communities in Malaysia. Socio-demographics, anti-hypertensive treatment details and an average of at least two blood pressure measurements were obtained.

Results: The age-adjusted prevalence was $42.0 \%$ (Cl: 40.9-43.2) and was higher in men [43.5 \% (Cl: 41.2-45.0)] than women [41.0 \% (Cl: 39.8-42.3)]. Participants from rural areas (APR: 1.12, Cl: 1.04-1.20); aged at least 40-49 years (APR: 1.86, Cl: 1.62-2.14); who were overweight (APR: 1.24, Cl: 1.15-1.34) and obese (APR: 1.54, Cl: 1.43-1.6) were more likely to have hypertension. The Indigenous ethnic group was less likely to be aware (APR: 0.81, Cl: 0.69-0.92) and to be on treatment (APR: $0.66, \mathrm{Cl}: 0.55-0.79$ ). Those in rural areas were less likely to have their hypertension controlled (APR: 0.61, Cl: 0.49-0.75). On the other hand, control was more likely in females (APR: 1.25, Cl: 1.01-1.54) and Indigenous group (APR: 1.64, Cl: 1.19-2.25).

Conclusion: Hypertension is common in the Malaysian adults. The control of hypertension has increased over the years but is still quite low. Public health measures, as well as individual interventions in primary care are crucial to reduce their risk of developing complications.
\end{abstract}

Keywords: Prevalence, Awareness, Treatment, Control, Hypertension, Malaysia

\section{Background}

Hypertension is the number one cardiovascular risk factor and the leading cause of mortality worldwide [1]. Malaysia, like other developing countries is experiencing an upsurge in cardiovascular morbidity and mortality [2]. The emergence of cardiovascular disease as a leading

\footnotetext{
* Correspondence: drsuraya.abdulrazak@gmail.com

${ }^{1}$ Faculty of Medicine, Universiti Teknologi MARA, Selayang Campus, Jalan Prima Selayang 7, 68100 Batu Caves, Selangor, Malaysia

${ }^{2}$ Institute of Pathology, Laboratory and Forensic Medicine (I-PPerForM), Universiti Teknologi MARA, Selayang Campus, Jalan Prima Selayang 7, 68100 Batu Caves, Selangor, Malaysia

Full list of author information is available at the end of the article
}

cause of death in Malaysia runs parallel with the rapid economic growth and associated socio-demographic change that has occurred over the past few decades. Thus, achieving blood pressure (BP) control and prevention of cardiovascular morbidity and mortality is vital and should be strived for, as many effective and inexpensive BP treatments options are now available.

Data on prevalence, awareness, treatment and control in various communities are necessary for monitoring and developing new strategies for hypertension control. A few reports have documented the national prevalence, awareness and treatment rates in Malaysia [2-5]. A 
national health morbidity survey (NHMS) conducted in 2011 among adults aged $\geq 18$ years reported that the overall prevalence of hypertension was $32.7 \%$ and the treatment rate of those who were aware was $78.4 \%$ [4]. Another study conducted a decade ago reported that the overall prevalence, treatment and control among individuals aged $\geq 15$ years were $27.8 \%, 32.4 \%$ and $8.6 \%$ respectively [3]. Although local data on the prevalence, awareness, treatment and control of hypertension were available, data on variation between urban and rural settings and body mass index (BMI) are still lacking. Such information is vital to guide the allocation of resources towards developing strategies for better detection and control of hypertension in Malaysia. Therefore, this study aimed to evaluate the prevalence, treatment, awareness and control of hypertension in Malaysia and the association with socio-demographic factors including urban-rural and BMI variations.

\section{Methods}

Sampling methods: The REDISCOVER Study is an ongoing prospective cohort study involving Malaysian adults aged $\geq 30$ years from 18 urban and 22 rural communities from the states of Selangor, Negeri Sembilan, Pahang, Kelantan, Sarawak and Sabah, and the Federal Territory of Kuala Lumpur. Participants were selected in a four-stage sampling process: selecting the states and then the 'communities', followed by households within them and finally individuals within the households. The 5 states were chosen to ensure adequate representation of the major ethnic groups in Malaysia. A standardized method of recruitment was adopted. All household members aged $\geq$ 30 years were invited to attend screening sessions in local community centres. Approximately, 20000 invitations were sent out. A response rate of $60-70 \%$ was recorded at each site. At the screening sites, participants were given information leaflet about the study and were screened for eligibility. Written informed consent was obtained from those who were eligible and willing to participate.

The baseline data was collected from 2007 to 2011. The study duration is 15 years and data collection is repeated every three years. The cross-sectional analytic sample presented in this paper consisted of 11,288 participants who were recruited at baseline. A detailed description of the design and methodology of this study has been published elsewhere [6]. The institutional ethics committee approved the study protocol.

Study procedures: All interviewers and investigators were trained regarding the study procedures prior to the conduct of the study in order to standardize the data collection and to minimize variability during data collection. Standardized, pre-tested, interviewer-based questionnaires were used to collect information regarding age, gender, ethnic group, educational level, smoking status, and known history and treatment of hypertension.
The blood pressure was measured at least twice at five minutes apart on the right arm supported at heart level, using Omron automatic digital blood pressure monitor (Omron HEM-757). Participants were advised not to smoke, exercise or eat in the last $30 \mathrm{~min}$, not to climb stairs in the last $15-30 \mathrm{~min}$, and were made to rest for at least five minutes before the measurements were taken. The average of the two BP readings was used for analysis. If the measurements differ by $5 \mathrm{mmHg}$ of either systolic or diastolic readings, subsequent measurements were taken at 5-10 min apart. The process was repeated until two BP values, which did not differ by more than $5 \mathrm{mmHg}$ of either systolic or diastolic readings, were obtained. The average of these two BP readings was used as the BP value for that particular subject.

Definitions of socio-demographic factors: Urban and rural areas were defined according to the Malaysian Population and Housing Census 2000 [7]. Gazetted areas with a combined population of 10,000 or more were identified as urban areas and all the other areas with a population of less than 10,000 were classified as rural. Ethnic groups were categorized as Malays, Chinese, Indians and Indigenous. Kadazan-Dusun, Bajau, Murut and several other ethnic minorities who live in East Malaysia represented the Indigenous group. Education attainment levels were classified into four categories as 'no formal education', 'primary', 'secondary' and 'tertiary'. Participants who had never been to school to get any form of education were categorised into 'no formal education', while 'primary' education level represented those with at least 7 years of schooling at primary school. 'Secondary' education level represented those with at least 5 years of schooling at secondary school, whereas 'tertiary' education level represented those who attended colleges or universities. Current smokers were defined as participants who were currently smoking cigarettes or had smoked cigarettes within the past five years. Ex- smokers were those who had stopped smoking for more than five years and non-smokers were those who had never smoked. BMI was classified according to the Malaysia Guideline on the Management of Obesity, 2004 [8]. Underweight was defined as $B M I<18.5 \mathrm{~kg} / \mathrm{m}^{2}$, normal range as BMI of $18.5-22.9 \mathrm{~kg} / \mathrm{m}^{2}$, overweight as BMI of $23-27.4 \mathrm{~kg} / \mathrm{m}^{2}$ and obesity as BMI $\geq 27.5 \mathrm{~kg} / \mathrm{m}^{2}$.

Definition of hypertension, awareness, treatment and control: Hypertension was defined according to the Malaysia Guideline on the Management of Hypertension, $3^{\text {rd }}$ Edition, 2008. "Hypertension" was considered to be present if: (1) the average systolic $\mathrm{BP} \geq 140 \mathrm{mmHg}$ and/or average diastolic $\mathrm{BP} \geq 90 \mathrm{mmHg}$; (2) or the participants reported a history of hypertension; (3) or participants reported taking anti-hypertensive medications in the past two weeks. "Awareness of hypertension" was defined as self-report of any previous diagnosis of hypertension by a healthcare professional among those with hypertension. 
"Treatment of hypertension" was defined as self-reported use of antihypertensive medications among those with hypertension. "Control among hypertensive participants" was defined as having a $\mathrm{BP}<140 / 90 \mathrm{mmHg}$ among those with hypertension.

\section{Data analysis}

Our study population was described in terms of its socio-demographic characteristics using simple descriptive statistics. Data were presented as percentages for categorical variables and numerical variables were described with mean $( \pm$ Standard Deviation $[S D])$. The overall prevalence of hypertension, awareness, treatment and control were described for the total study population with $95 \%$ confidence interval (CI). The prevalence of hypertension was also age standardized using World Health Organisation (WHO) world population for people aged 30 years and above. The modified Poisson regression model with robust variance was used to estimate the crude and adjusted prevalence ratio $[9,10]$ in this study. To identify independent factors associated of being hypertensive, aware, treated and controlled; location, gender, age, ethnicity, education attainment, smoking status and BMI were controlled for each other using the modified Poisson regression model. The crude prevalence ratios (CPR) were compared to adjusted prevalence ratios (APR) and their $95 \%$ CI. A twosided P-value of $<0.05$ was considered to be statistically significant. All analyses were performed using STATA software version 11.1 with (StataCorp.TX).

\section{Results}

\section{Characteristics of the respondents}

A total of 11288 eligible adults participated in this study. Table 1 shows the socio-demographic characteristics of the participants by locality, age, gender, ethnicity, education attainment, smoking status and BMI. The mean age was 53.02 ( $\mathrm{SD} \pm 10.9)$ years. There were more participants from urban areas $(51.9 \%)$ and females $(56.2 \%)$. Majority of the participants were Malays (72.5\%), followed by Indigenous group (13.8\%), Chinese (10.8\%) and Indians (2.9\%). In terms of education attainment, $38.4 \%$ of the participants had secondary education level and majority had never smoked cigarette $(75.6 \%)$. The proportions of participants who were overweight and obese were $38.7 \%$ and $34.3 \%$, respectively.

\section{Prevalence of hypertension, awareness, treatment and control}

Table 2 shows the overall prevalence of hypertension, awareness, treatment, and control by locality, gender, ethnicity, education attainment, smoking status and BMI. The overall prevalence of hypertension in our sample was $47.9 \%$ (CI: 47.0-49.0). The age-adjusted prevalence was $42.0 \%$ (CI: 40.9-43.2) and was higher in men
Table 1 Demographic characteristics

\begin{tabular}{|c|c|}
\hline \multicolumn{2}{|c|}{ Demographic characteristics } \\
\hline All subjects $(n, \%)$ & $11,288(100)$ \\
\hline Mean age in years $( \pm S D)$ & $53.02( \pm 10.9)$ \\
\hline \multicolumn{2}{|l|}{ Gender $(n, \%)$} \\
\hline Male & $4943(43.8)$ \\
\hline Female & $6345(56.2)$ \\
\hline \multicolumn{2}{|l|}{ Location ( $\left.n^{\mathrm{a}}, \%\right)$} \\
\hline Urban & $5857(51.9)$ \\
\hline Rural & $5410(48.1)$ \\
\hline \multicolumn{2}{|l|}{ Age (years) $(n, \%)$} \\
\hline $30-39$ & $1233(10.9)$ \\
\hline $40-49$ & $3336(29.6)$ \\
\hline $50-59$ & 3606 (31.9) \\
\hline$\geq 60$ & $3113(27.6)$ \\
\hline \multicolumn{2}{|l|}{ Ethnicity $(n, \%)$} \\
\hline Malay & $8188(72.5)$ \\
\hline Chinese & $1214(10.8)$ \\
\hline Indian & $327(2.9)$ \\
\hline Indigenous group & $1559(13.8)$ \\
\hline \multicolumn{2}{|c|}{ Education attainment $\left(n^{\mathrm{a}}, \%\right)$} \\
\hline No formal education & $1566(15.3)$ \\
\hline Primary & $2766(27.0)$ \\
\hline Secondary & 3929 (38.4) \\
\hline Tertiary & $1980(19.3)$ \\
\hline \multicolumn{2}{|l|}{ Smoking status $\left(n^{\mathrm{a}}, \%\right)$} \\
\hline Non smoker & 8014 (75.6) \\
\hline Current smoker & $1367(12.9)$ \\
\hline Ex-smoker & $1224(11.5)$ \\
\hline \multicolumn{2}{|l|}{ Body Mass Index $\left(n^{\mathrm{a}}, \%\right)$} \\
\hline Underweight & $392(3.7)$ \\
\hline Normal & $2493(23.3)$ \\
\hline Overweight & $4144(38.7)$ \\
\hline Obese & 3670 (34.3) \\
\hline
\end{tabular}

$n^{a}$ is not equal to 11288 due to missing values

[43.5 \% (CI: 41.2-45.0)] than women [41.0 \% (CI: 39.842.3)]. Out of those who have hypertension, $53.2 \%$ (CI: 51.9-54.5) were aware, $38.2 \%$ (CI: 36.9-39.5) were on treatment, and $15.9 \%$ (CI: 14.9-16.9) had their BP controlled. Out of those who were aware, $72.3 \%$ (CI: 70.673.9) received treatment and $30.3 \%$ (CI: 28.7-32.0) had their BP controlled. Out of those who were treated, 30.7 \% (CI: 28.7-32.7) achieved BP control.

In terms of locality, there was a significantly higher prevalence of hypertension in the rural than in urban areas $(51.2 \%$ vs. $44.9 \%, p<0.001)$. However, there was a significantly lower prevalence of treatment $(34.7 \%$ vs. $42.0 \%, p<0.001)$ and control $(13.1 \%$ vs. $18.9 \%, p<0.001)$ 
Table 2 The overall prevalence, awareness, treatment and control of hypertension according to selected population characteristics

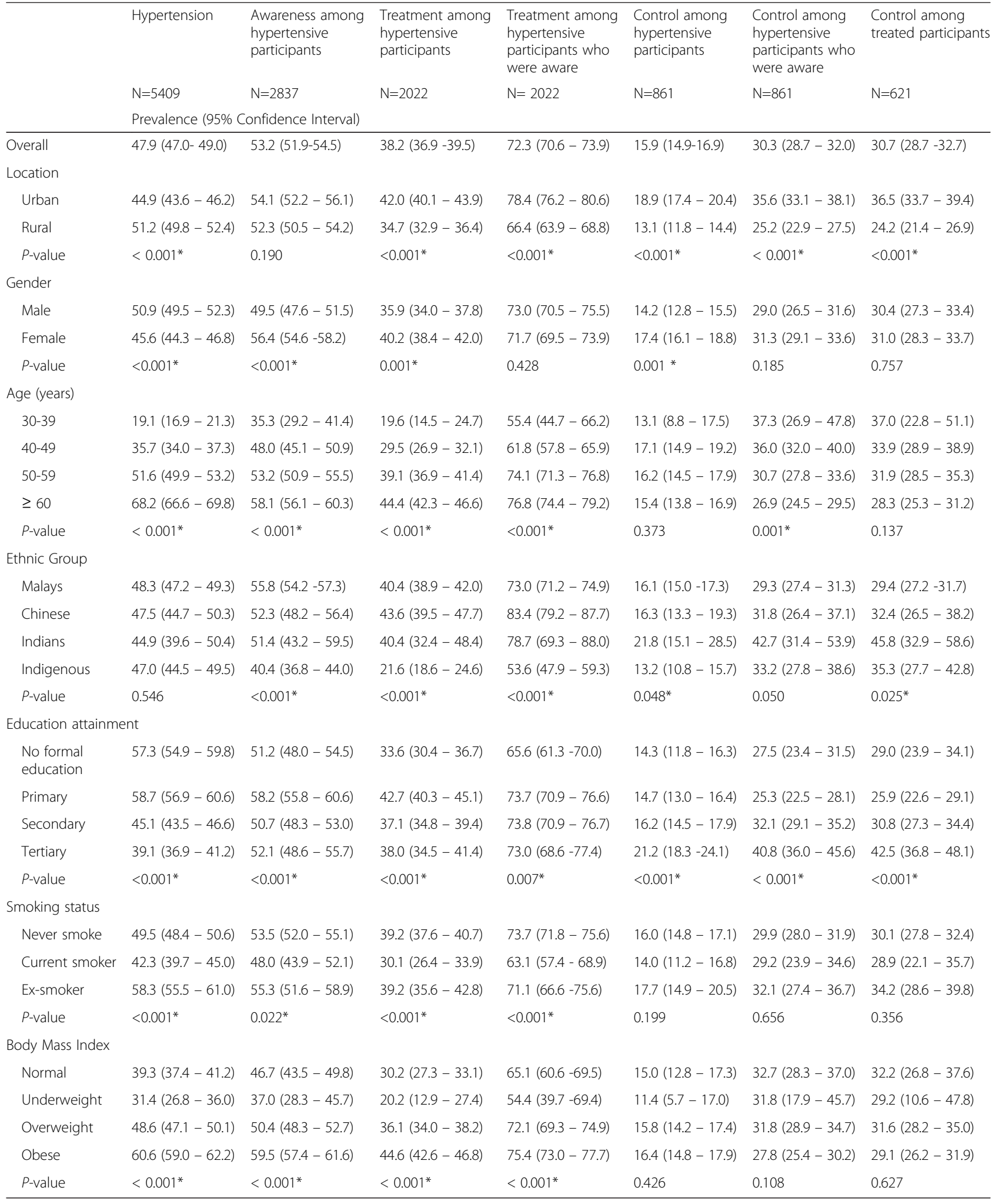

* significant at $p<0.05$ 
among hypertensive participants in the rural compared to urban areas, respectively. Among those who were aware, there was also a significantly lower prevalence of treatment ( $66.4 \%$ vs. $78.4 \%, p<0.001)$ and control $(25.2 \%$ vs. $35.6 \%$, $p<0.001)$ in the rural compared to urban areas. Out of those who were treated, there was also a significantly lower prevalence of control $(24.2 \%$ vs. $36.5 \%, p<0.001)$ in the rural compared to urban areas.

Males had a significantly higher prevalence of hypertension compared to females, $(50.9 \%$ vs. $45.6 \%, p<$ 0.001). However, a significantly lower prevalence of awareness $(49.5 \%$ vs. $56.4 \%, p<0.001)$, treatment $(35.9 \%$ vs. $40.2 \%, p=0.001)$ and control $(14.2 \%$ vs.17.4 $\%, p=0.001)$ were observed in males compared to females among hypertensive participants. With regards to age, participants aged $\geq 60$ years had the highest prevalence of hypertension (68.2 \%), awareness $(58.1 \%)$ and treatment $(44.4 \%)$ compared to the other age groups.

There was no significant difference of prevalence of hypertension among the ethnic groups. Malays had the highest prevalence of awareness (55.8 \%) while Chinese had the highest prevalence of treatment (43.6 \%) compared to other ethnic groups. In contrast, the Indigenous group had the lowest prevalence of awareness (40.4\%) and treatment $(21.6 \%)$ compared to other ethnic groups. These trends were significant.

Participants with primary education attainment had the highest prevalence of hypertension (58.7\%), awareness $(58.2 \%)$ and treatment $(42.7 \%)$ compared to those in other education levels. Meanwhile, those with tertiary education level had the highest prevalence of control $(21.2 \%)$ compared to those in other education levels. These trends were significant. Ex- smokers had the highest prevalence of hypertension (58.3 \%). In contrast, current smokers had the lowest prevalence of awareness $(48.0 \%)$ and treatment $(30.1 \%)$ compared to nonsmokers or ex-smokers. Obese participants had the highest prevalence of hypertension (60.6\%), awareness $(59.5 \%)$ and treatment (44.6\%) compared to those in other BMI categories.

Socio-demographic factors associated with hypertension, awareness, treatment and control

Table 3 shows factors associated with hypertension, awareness, treatment and control among treated hypertensive participants. In a modified Poisson regression model that controlled for location, gender, age, ethnicity, education level, smoking status and BMI, the independent factors associated with hypertension were residing in the rural areas, female, age, Chinese, tertiary education, current smoker and all BMI categories. Meanwhile, the factors associated with awareness among the hypertensive participants were female, age, Indigenous groups and being obese. Factors associated with treatment among hypertensive participants were female, age, Indigenous groups and being overweight or obese. With regards to factors associated with control among treated participants, residing in the rural areas, female and Indian were identified as the independent factors.

\section{Discussion}

The REDISCOVER Study provided evidence that nearly one in two (overall prevalence $=47.9 \%$; age-adjusted prevalence $=42.0 \%$ ) Malaysians over 30 years of age were hypertensive and its treatment and control were still inadequate. Using the same age cut off $\geq 30$ years old, this study showed a rising overall prevalence of hypertension compared to the NHMS 2011 (43.5\%) [4], NHMS III 2006 (42.6\%) [11] and NHMS II 1996 (32.9\%) [5]. In addition, when comparing Malaysia to the other South East Asian countries, Malaysia had the highest prevalence of hypertension among adults $\geq 18$ years $(32.7 \%$ ) according to NHMS 2011 [4] compared to Singapore (26.6\%), Indonesia (23.\%) and Thailand (20.5\%) [12]. A similar rising trend is also observed in the prevalence of other associated cardiovascular risk factors among the Malaysian population e.g. obesity and dyslipidaemia [6]. Urbanization phenomenon, sedentary lifestyle, high consumption of salt and fatty food may have contributed to the rising prevalence of hypertension and the associated cardiovascular risk factors in Malaysia [13].

With regards to the awareness rate in Malaysian adults $\geq 30$ years of age, REDISCOVER showed a higher awareness (53.2 \%) compared to NHMS 2011 (42.5\%) [4], NHMS III (35.8 \%) [11] and NHMS II (33.0 \%) [5]. Nevertheless, a much higher rate of awareness was observed in a developed country like the USA (82.9 \% in men and $80.3 \%$ in women $\geq 30$ years) [14] and also amongst the rural community in Thailand (64.9\%) [15]. Despite an improved awareness, the treatment rate observed in this study was lower when compared to Thailand (38.2 vs. $42.6 \%$ ) [15] and has not changed much compared to an earlier local study (32.4\%) [3]. However, the treatment rate was comparable to countries like China (34.1\%) [16] and Turkey (37.7 \%) [17]. Among hypertensive participants in this study who were aware of their hypertension status, the treatment rate (72.3\%) was comparable to the finding in NHMS 2011 (78.4\%) [4].

An improved overall control rate was observed in this study (15.9\%) when compared to NHMS III (8.2 \%) [11] and NHMS II (6 \%) [5]. Similarly, this study showed an improvement in the control rate amongst those on treatment (30.7 \%) compared to NHMS III and II which showed a stagnant rate of $26.0 \%$ [5, 11]. The improvements in the awareness, treatment and control rates over the last decades may have been attributed to the various 
Table 3 Factors associated with prevalence of hypertension, awareness, treatment and control among treated hypertensive participants

\begin{tabular}{|c|c|c|c|c|c|c|c|c|}
\hline \multirow[t]{2}{*}{ Risk Factors } & \multicolumn{2}{|l|}{ Hypertension } & \multicolumn{2}{|c|}{ Awareness among hypertensive participants } & \multicolumn{2}{|c|}{ Treatment among hypertensive participants } & \multicolumn{2}{|c|}{ Control among treated participants } \\
\hline & $\mathrm{CPR}(\mathrm{Cl})$ & APR+ (Cl) & $\mathrm{CPR}(\mathrm{Cl})$ & APRt (Cl) & $\mathrm{CPR}(\mathrm{Cl})$ & APRt (Cl) & $\mathrm{CPR}(\mathrm{Cl})$ & APRt (Cl) \\
\hline \multicolumn{9}{|l|}{ Location } \\
\hline Urban & 1.00 & 1.00 & 1.00 & 1.00 & 1.00 & 1.00 & 1.00 & 1.00 \\
\hline Rural & $1.14(1.08-1.20)^{* *}$ & $1.12(1.04-1.20)^{*}$ & $0.97(0.9-1.04)$ & $1.03(0.94-1.13)$ & $0.83(0.76-0.90)^{* *}$ & $0.95(0.85-1.06)$ & $0.66(0.56-0.78)^{* *}$ & $0.61(0.49-0.75)^{* *}$ \\
\hline \multicolumn{9}{|l|}{ Gender } \\
\hline Male & 1.00 & 1.00 & 1.00 & 1.00 & 1.00 & 1.00 & 1.00 & 1.00 \\
\hline Female & $0.90(0.85-0.95)^{* *}$ & $0.88(0.83-0.94)^{* *}$ & $1.14(1.06-1.23)^{*}$ & $1.19(1.08-1.31)^{* *}$ & $1.12(1.02-1.22)^{*}$ & $1.13(1.01-1.26)^{*}$ & $1.02(0.87-1.2)$ & $1.25(1.01-1.54)^{*}$ \\
\hline \multicolumn{9}{|l|}{ Age (years) } \\
\hline $30-39$ & 1.00 & 1.00 & 1.00 & 1.00 & 1.00 & 1.00 & 1.00 & 1.00 \\
\hline $40-49$ & $1.86(1.62-2.14)^{* *}$ & $1.71(1.48-1.98)^{* *}$ & $1.36(1.08-1.71)^{*}$ & $1.30(1.03-1.65)^{*}$ & $1.51(1.11-2.05)^{*}$ & $1.50(1.09-2.07)^{*}$ & $0.92(0.55-1.53)$ & $0.92(0.54-1.55)$ \\
\hline $50-59$ & $2.70(2.35-3.09)^{* *}$ & $2.37(2.06-2.74)^{* *}$ & $1.51(1.2-1.89)^{* *}$ & $1.45(1.15-1.83)^{*}$ & $2.00(1.48-2.69)^{* *}$ & $1.98(1.45-2.70)^{* *}$ & $0.86(0.53-1.41)$ & $0.85(0.51-1.42)$ \\
\hline$\geq 60$ & $3.56(3.12-4.08)^{* *}$ & $3.17(2.74-3.67)^{* *}$ & $1.65(1.32-2.06)^{* *}$ & $1.63(1.29-2.06)^{* *}$ & $2.27(1.69-3.05)^{* *}$ & $2.36(1.73-3.24)^{* *}$ & $0.77(0.47-1.25)$ & $0.77(0.46-1.31)$ \\
\hline \multicolumn{9}{|l|}{ Ethnicity } \\
\hline Malay & 1.00 & 1.00 & 1.00 & 1.00 & 1.00 & 1.00 & 1.00 & 1.00 \\
\hline Chinese & $0.99(0.9-1.08)$ & $1.12(1.01-1.24)^{*}$ & $0.94(0.83-1.06)$ & $1.01(0.88-1.16)$ & $1.08(0.94-1.24)$ & $1.13(0.97-1.32)$ & $1.10(0.87-1.40)$ & $0.90(0.69-1.18)$ \\
\hline Indian & $0.93(0.79-1.1)$ & $1.04(0.87-1.24)$ & $0.92(0.73-1.16)$ & $0.95(0.74-1.22)$ & $1.00(0.77-1.30)$ & $1.00(0.76-1.33)$ & $1.56(1.06-2.29)^{*}$ & $1.35(0.89-2.04)$ \\
\hline Indigenous groups & $0.97(0.9-1.05)$ & $1.04(0.95-1.14)$ & $0.72(0.64-0.82)^{* *}$ & $0.80(0.69-0.92)^{*}$ & $0.53(0.45-0.63)^{* *}$ & $0.66(0.55-0.79)^{* *}$ & $1.20(0.91-1.59)$ & $1.64(1.19-2.25)^{*}$ \\
\hline \multicolumn{9}{|l|}{ Education attainment } \\
\hline No formal education & 1.00 & 1.00 & 1.00 & 1.00 & 1.00 & 1.00 & 1.00 & 1.00 \\
\hline Primary & $1.03(0.94-1.11)$ & $1.00(0.92-1.1)$ & $1.14(1.02-1.27)^{*}$ & $1.09(0.96-1.22)$ & $1.27(1.11-1.46)^{*}$ & $1.15(1.00-1.33)$ & $0.89(0.69-1.15)$ & $1.03(0.78-1.35)$ \\
\hline Secondary & $0.79(0.73-0.85)^{* *}$ & $0.94(0.85-1.03)$ & $0.99(0.88-1.11)$ & $0.99(0.86-1.12)$ & $1.11(0.96-1.27)$ & $1.05(0.9-1.23)$ & $1.06(0.83-1.37)$ & $1.03(0.77-1.38)$ \\
\hline Tertiary & $0.68(0.62-0.75)^{* *}$ & $0.86(0.76-0.96)^{*}$ & $1.02(0.89-1.16)$ & $1.05(0.89-1.23)$ & $1.13(0.96-1.33)$ & $1.07(0.89-1.3)$ & $1.46(1.11-1.93)^{*}$ & $1.30(0.94-1.81)$ \\
\hline \multicolumn{9}{|l|}{ Smoking status } \\
\hline Never smoke & 1.00 & 1.00 & 1.00 & 1.00 & 1.00 & 1.00 & 1.00 & 1.00 \\
\hline Current smoker & $0.86(0.78-0.93)^{* *}$ & $0.81(0.73-0.89)^{* *}$ & $0.90(0.79-1.02)$ & $0.99(0.86-1.14)$ & $0.77(0.66-0.90)^{*}$ & $0.84(0.7-1.00)$ & $0.96(0.72-1.28)$ & $1.11(0.79-1.55)$ \\
\hline Ex-smoker & $1.18(1.09-1.27)^{* *}$ & $1.00(0.91-1.09)$ & $1.03(0.93-1.15)$ & $1.12(0.98-1.26)$ & $1.00(0.88-1.14)$ & $1.04(0.9-1.21)$ & $1.13(0.91-1.41)$ & $1.28(0.99-1.67)$ \\
\hline \multicolumn{9}{|l|}{ Body Mass Index } \\
\hline Normal & 1.00 & 1.00 & 1.00 & 1.00 & 1.00 & 1.00 & 1.00 & 1.00 \\
\hline Underweight & $0.80(0.66-0.96)^{*}$ & $0.72(0.59-0.89)^{*}$ & $0.79(0.58-1.08)$ & $0.77(0.56-1.08)$ & $0.67(0.44-1.01)$ & $0.69(0.45-1.07)$ & $0.91(0.42-1.95)$ & $1.31(0.6-2.87)$ \\
\hline Overweight & $1.24(1.15-1.34)^{* *}$ & $1.31(1.2-1.42)^{* *}$ & $1.08(0.97-1.21)$ & $1.10(0.98-1.24)$ & $1.20(1.04-1.37)^{*}$ & $1.19(1.03-1.38)^{*}$ & $0.98(0.77-1.25)$ & $0.95(0.74-1.23)$ \\
\hline Obese & $1.54(1.43-1.66)^{* *}$ & $1.71(1.58-1.86)^{* *}$ & $1.28(1.15-1.42)^{* *}$ & $1.30(1.16-1.46)^{* *}$ & $1.48(1.3-1.69)^{* *}$ & $1.51(1.31-1.74)^{* *}$ & $0.90(0.72-1.14)$ & $0.88(0.68-1.13)$ \\
\hline
\end{tabular}

tModified Poisson regression model

CPR: Crude prevalence ratio, APR: Adjusted prevalence ratio, Cl: $95 \%$ confidence interval

*significant at $p<0.05 ;{ }^{*}$ significant at $p<0.001$ 
public health and primary care measures mooted by the Health Ministry. These include continuous enhancement of the public primary care services, as well as improvements in the availability of antihypertensive agents in health clinics where majority of the hypertensive individuals are managed. Nevertheless, efforts to heighten public awareness, treatment and control should be continued and further enhanced.

Globally, the prevalence of hypertension in the urban adult populations were between $15-35 \%$ but was found to be lower in the rural Asian populations [18]. Interestingly, in comparing the urban and rural populace in this study, there was a higher prevalence of hypertension in the rural compared to the urban population $(51.2 \%$ vs. $44.9 \%$ ). Rural population was found to be more likely to have hypertension (APR: 1.12, CI: 1.04-1.20). This is in contrast to studies in Africa [19, 20] and India [21] where higher prevalence of hypertension were observed in their urban populations. The higher prevalence of hypertension in the rural population in this study could be explained by lifestyle factors such as physical inactivity, excess dietary intake of sodium and fat as well as obesity which have spread from urban to rural areas at an alarming rate [13]. A strong correlation between urbanization and prevalence of hypertension was also evidenced in India, where a sharp increase in per capita net domestic product, growth production and human development indexed correlated positively with the hypertension increase in rural areas [22]. A significantly lower control rates in the rural areas were observed in this study which were similar to other studies in China and Thailand [23, 24]. Rural population was less likely to achieve control (APR 0.61; CI: 0.49-0.75) compared to their urban counterparts. Poorer BP control in the rural participants may be due to lack of knowledge on hypertension and disparity in healthcare services available in the rural compared to urban areas. The geographical condition of East Malaysia that is still preserved with the tropical rain forest and rivers as the main transportation method remains a challenge in establishing good access to healthcare. The other possibility is the use of complementary and alternative medicines as part of selfmanagement and this was found to be prevalent in rural areas [25]. This study highlights the need to put more efforts to reduce the prevalence and increase the control of hypertension in the rural areas of Malaysia.

In evaluating gender differences, a higher age adjusted prevalence of hypertension was observed in males than in females. However, females had a significantly higher prevalence of awareness, treatment and control which were consistent with other studies $[15,26]$. In the regression analyses, females were less likely to have hypertension (APR 0.88; CI: 0.83-0.94) but they were more likely to be aware (APR 1.19; CI: 1.08-1.31), to be treated (APR 1.13;
CI: 1.01-1.26) and to achieve BP control once treated (APR 1.25; CI: 1.01-1.54) when compared to males. This data suggests the importance of raising hypertension awareness as well as controlling hypertension in men. A recent review highlighted the importance of promoting and improving men's health in the country due to a higher prevalence of cardiovascular risk factors and an increasing cancer related death among men [27]. Barriers to health seeking behaviour among men include lack of time to adopt healthy lifestyle, men's enjoyment to be among fellow smokers and men's perception of invulnerability to illness [28]. More studies are needed to identify effective strategies to improve men's health seeking behavior and efforts to improve men's health should be in place.

Published evidences have shown that older age was associated with a higher prevalence, awareness and treatment of hypertension [29-31] which were consistent with findings from REDISCOVER. Participants aged $\geq 60$ years old were found to be three times more likely to have hypertension (APR 3.17; CI 2.74-3.67), almost twice more likely to be aware (APR 1.63; CI: $1.29-2.06$ ) and twice more likely to be on treatment (APR 2.36; CI 1.73-3.24) compared to participants aged 30-39 years in the study. It was postulated that older people who are at higher cardiovascular risk have better awareness and hence receive treatment more than younger individuals. It is concerning to note that younger individuals were less aware of their hypertension status and were less likely to be on antihypertensive treatment. Hence, it is important to educate younger individuals to have regular health screening and to seek treatment early in order to minimize cardiovascular complications.

There was no significant difference in prevalence of hypertension among the ethnic groups in this study. Earlier studies conducted locally noted that all ethnic groups were found to have uniformly high prevalence of hypertension [2, 3]. REDISCOVER also found that the Indigenous groups who resided in the remote areas were less likely to be aware (APR 0.8; CI: 0.69-0.92) and to be on treatment (APR 0.66; CI: 0.55-0.79) for hypertension compared to the Malays.

This study shows that participants with primary education level had the highest prevalence of hypertension, awareness and treatment, while those with tertiary education level had the highest prevalence of control. Those with tertiary education level were also found to be less likely to have hypertension (APR 0.86; CI: 0.76-0.96). This trend was also found in another study [32]. Those with lower education attainment may be leading a less healthy lifestyle to explain the higher prevalence of hypertension, and may have a lack of knowledge on the importance of good hypertension control. This finding underlines the needs to deliver better patient education targeting those with lower education level. 
Ex-smokers had a significantly higher prevalence of hypertension than non-smokers or current-smokers. This finding was supported by other study which found that the prevalence of hypertension was higher in former smokers than non-smokers and the risk was associated with higher body mass and higher prevalence of obesity in ex-smokers [33]. However, further regression analyses found that current smokers were found to be less likely (APR 0.81; CI: 0.73-0.89) to have hypertension compared to non-smokers. Further studies are needed to understand the effects of smoking status and hypertension. Nonetheless, smoking was identified as a risk factor for development of hypertension [34].

Overweight and obese participants in this study were found to have the highest prevalence of hypertension compared to those in the other BMI categories. Participants who were overweight (APR 1.31; CI: 1.20-1.42) and obese (APR 1.71; CI: 1.58-1.86) were found to be more likely to have hypertension, which support the postulation that obesity are risk factors for hypertension $[16,32,35]$. It was reported that Asian populations are more inclined to obesity with increased insulin resistance compared to their Western counterparts [36]. Hence, with increasing globalization together with hazardous behaviour which are highly prevalent in Malaysia e.g. smoking [37], high fat intake and low physical activity $[13,38]$; concerted efforts need to be taken to reduce these modifiable risk factors in our population.

REDISCOVER gave insight on the current magnitude of hypertension burden in the Malaysian population. Higher hypertension prevalence would translate into higher number of individuals with future cardiovascular diseases and events; leading to increased utilization of healthcare services, escalating health care costs, increased premature deaths, reduced productivity and increased economic burden [1, 39]. Public health measures, as well as individual interventions in primary care are crucial to reduce this rising epidemic. Public health measures should include multi-sectorial collaborations involving relevant stakeholders in the community. At the primary care level, individual patients aged $\geq 30$ years old should be routinely screened for hypertension and its associated cardiovascular risk factors at regular intervals and at opportunistic times. Special attention should be given to groups most affected and those who were least aware, treated and controlled. These include the rural population, male participants, Indigenous group, younger, overweight and obese individuals. Programs may incorporate intervention to improve the knowledge, attitude and behaviours of patients and health care professionals in order to diagnose hypertension early and improve adherence to treatment to achieve better control and prevent complications.

This study has several limitations. First, comparisons in the prevalence of hypertension, awareness, treatment and control rates with other countries may be hindered by the different methodologies and criteria used between studies. Second, information bias may have been present with respect to both recall diagnosis of hypertension and treatment. However, proper training of all manpower involved in conducting the survey and its procedures minimized potential bias. Third, two measurements of BP on a single visit were used to diagnose hypertension in this study as opposed to the recommendation by the Malaysian CPG of Management of Hypertension, $3^{\text {rd }}$ edition, 2008, which recommended BP measurements on at least 2 separate visits for diagnosis [40]. However, similar method was used to diagnose hypertension in the other national surveys and several other studies due to the difficulties to measure $\mathrm{BP}$ on 2 separate visits in large population surveys [3, 41]. Fourth, Malays were over represented, while Chinese and Indian populations were under represented in this study as Malaysia's ethnic population comprises 53.3 \% Malays, 26.0 \% Chinese, $7.7 \%$ Indians and the remaining $13 \%$ are of other ethnic groups [7]. Our study population also had more females and older individuals than the Malaysian population. This may be due to the fact that males and younger participants were working when screenings were conducted, or females were more health conscious and therefore, were more likely to attend health screening programmes. Hence, interpretation of the result should be done with caution. Nevertheless, the large sample size of this study population should counter balance any possible bias in the sampling.

\section{Conclusion}

In conclusion, REDISCOVER highlights an alarming situation as almost half of Malaysian adults aged $\geq 30$ years have hypertension and of those, only half were aware of their hypertension status, less than $40 \%$ were on treatment and only a third of those were controlled. Comprehensive intervention strategies that target the general population, as well as focus on improving awareness, treatment and control among rural population, men, younger individuals, Indigenous groups, overweight and obese individuals must be put in place. Findings from this study emphasize the urgency to stem the rising tide of hypertension prevalence and the almost inevitable emerging epidemic of cardiovascular diseases in Malaysia. Public health measures, as well as individual interventions in primary care are crucial to reduce their risk of developing complications.

\section{Availability of data and materials}

Data are kept at the Centre for Translational Research and Epidemiology (CenTRE), Faculty of Medicine, Universiti Teknologi MARA. Data will be shared upon request and it is subjected to the data protection regulations. 


\section{Abbreviations}

APR: adjusted prevalence ratio; BMI: body mass index; BP: blood pressure; Cl: confidence interval; CPR: crude prevalence ratio; NHMS: National Health Morbidity Survey; SD: standard deviation.

\section{Competing interest}

The authors declare that they have no competing interests.

\section{Author's contributions}

SAR and ASR wrote the manuscript and were involved in the data collection of the REDISCOVER Study. AMD performed the statistical analysis and contributed to the critical discussion of the results. MM, MMY, NKK, FA, HAH, ADK, N-AMNK and NMN contributed to the critical revision of the manuscript and were involved in the data collection. HN verified the laboratory results and contributed to the critical revision of the manuscript. KY is the Principal Investigator of this study. He played a major role in the conception and design of the study, contributed to the critical revision of the manuscript and intellectual content, and provided expertise and oversight throughout the process. All authors read and approved the final version.

\section{Acknowledgement}

The authors acknowledge the following REDISCOVER Investigators for their contributions towards the study: Fadhlina Abdul Majid, Najmin Abu Bakar, Effarezan Abdul Rahman, Mohd Kamal Mohd Arsad, Mohd Yazrie Yacob, Rafezah Razali, Razif Dasiman, Rosiah Ahmad, Sarina Ali, Tengku Saifudin Tengku Ismail, and Zubin Othman Ibrahim. The authors also extend their appreciation to all participants and staff of the Faculty of Medicine, Universiti Teknologi MARA, for their contributions.

\section{Funding}

This research is funded by the Ministry of Higher Education (Grant no. 600RMI/LRGS 5/2 (2/2011)) and Ministry of Science, Technology and Innovation (Grant no. 07-05-IFN BPH 010).

\section{Author details}

${ }^{1}$ Faculty of Medicine, Universiti Teknologi MARA, Selayang Campus, Jalan Prima Selayang 7, 68100 Batu Caves, Selangor, Malaysia. ${ }^{2}$ Institute of Pathology, Laboratory and Forensic Medicine (I-PPerForM), Universiti Teknologi MARA, Selayang Campus, Jalan Prima Selayang 7, 68100 Batu Caves, Selangor, Malaysia. ${ }^{3}$ Faculty of Medicine \& Defence Health, National Defence University of Malaysia, 57000 Kuala Lumpur, Malaysia. ${ }^{4}$ Centre for Translational Research and Epidemiology (CenTRE), Faculty of Medicine, Universiti Teknologi MARA, 47000 Sungai Buloh, Selangor, Malaysia. ${ }^{5}$ UCSI University, UCSI Height, Cheras, 56000 Kuala Lumpur, Malaysia. ${ }^{6}$ Primary Care Medicine Discipline, Universiti Teknologi MARA, 68100 Selayang, Selangor, Malaysia.

\section{Received: 11 August 2015 Accepted: 8 April 2016}

\section{Published online: 21 April 2016}

\section{References}

1. Lawes CM, Vander HS, Rodgers A. Global burden of blood-pressure-related disease, 2001. Lancet. 2008:371:1513-8.

2. Lim TO, Morad Z. Prevalence, awareness, treatment and control of hypertension in the Malaysian adult population: results from the national health and morbidity survey 1996. Singapore Med J. 2004;45(1):20-7.

3. Rampal L, Rampal S, Azhar MZ, Rahman AR. Prevalence, awareness, treatment and control of hypertension in Malaysia: A national study of 16,440 subjects. Public Health. 2008:122(1):11-8.

4. Institute for Public Health, Ministry of Health Malaysia. National Health and Morbidity Survey 2011 (NHMS 2011) vol II: Non-Communicable Diseases. Kuala Lumpur. Institute for Public Health; 2011.

5. Institute for Public Health, Ministry of Health Malaysia. The Second National Health and Morbidity Survey (NHMS II) Report. Kuala Lumpur. Institute for Public Health; 1996

6. Ramli AS, Daher AM, Noor Khan Nor-Ashikin M, Mat-Nasir N, Keat Ng K, Miskan M, et al. JIS definition identified more Malaysian adults with metabolic syndrome compared to the NCEP-ATP III and IDF criteria. Biomed Res Int. 2013;2013:760963.

7. Malaysia Department of Statistic. Population distribution and basic demographic characteristics 2000, Dept of Statistics, Malaysia. Malaysia: Dept of Statistics; 2000.
8. Health Technology Assessment Section, Medical Development Division Ministry of Health, Malaysia. Clinical Practice Guideline on Management of Obesity. Putrajaya: Ministry of Health, Malaysia; 2004.

9. Coutinho LMS, Scazufca M, Menezes PR. Methods for estimating prevalence ratios in cross-sectional studies. Rev Saude Publica. 2008;42(6):992-8.

10. Barros AJD, Hirakata VN. Alternatives for logistic regression in cross-sectional studies: an empirical comparison of models that directly estimate the prevalence ratio. BMC Med Res Methodol. 2003;3:21.

11. Institute for Public Health, Ministry of Health, Malaysia. National Health and Morbidity Survey (NHMS III) Report. Kuala Lumpur, Institute for Public Health; 2006.

12. Kearney PM, Whelton M, Reynolds K, Muntner P, Whelton PK, He J. Global burden of hypertension-analysis of worldwide data. Lancet. 2005:365:217-23.

13. Ismail MN, Chee SS, Nawawi H, Yusoff K, Lim TO, James WPT. Obesity in Malaysia. Obes Rev. 2002;3(3):203-8.

14. Olives C, Myerson R, Mokdad AH, Murray CJ, Lim SS. Prevalence, awareness, treatment, and control of hypertension in United States Counties, 2001-2009. PLoS One. 2013;8(4):e60308.

15. Howteerakul N, Suwannapong N, Sittilerd R, Rawdaree P. Health risk behaviours, awareness, treatment and control of hypertension among rural community people in Thailand. Asia-Pacific J Public Heal. 2006;18(1):3-9.

16. Wang J, Zhang L, Wang F, Liu L, Wang H. Prevalence, awareness, treatment, and control of hypertension in China: results from a national survey. Am J Hypertens. 2014;27:1355-61.

17. Tugay Aytekin N, Pala K, Irgil E, Akis N, Aytekin H. Distribution of blood pressures in Gemlik district, north-west Turkey. Heal Soc Care Community. 2002;10(5):394-401.

18. Singh RB, Suh IL, Singh VP, Chaithiraphan S, Laothavorn P, Sy RG, et al. Hypertension and stroke in Asia: prevalence, control and strategies in developing countries for prevention. J Hum Hypertens. 2000;14(10-11):749-63.

19. Addo J, Smeeth L, Leon DA. Hypertension in Sub-Saharan Africa: a systematic review. Hypertension. 2007:50(6):1012-8.

20. Agyemang C. Rural and urban differences in blood pressure and hypertension in Ghana, West Africa. Public Health. 2006;120(6):525-33.

21. Anchala R, Kannuri NK, Pant H, Khan H, Franco OH, Di Angelantonio E, et al. Hypertension in India: a systematic review and meta-analysis of prevalence, awareness, and control of hypertension. J Hypertens. 2014;32(6):1170-7.

22. Das S, Sanyal K, Basu A. Study of urban community survey in India: growing trend of high prevalence of hypertension in a developing country. Int J Med Sci. 2005:2(2):70-8

23. Li H, Meng Q, Sun X, Salter A, Briggs NE, Hiller JE. Prevalence, awareness, treatment, and control of hypertension in rural China: results from Shandong Province. J Hypertens. 2010;28(3):432-8.

24. Aekplakorn W, Sangthong R, Kessomboon P, Putwatana P, Inthawong R, Taneepanichskul S, et al. Changes in prevalence, awareness, treatment and control of hypertension in Thai population, 2004-2009: Thai National Health Examination Survey III-IV. J Hypertens. 2012;30(9):1734-42.

25. Wilkinson JM, Jelinek $\mathrm{H}$. Complementary medicine use among attendees at a rural health screening clinic. Complement Ther Clin Pract Elsevier Ltd. 2009;15(2):80-4

26. Gu D, Reynolds K, Wu X, Chen J, Duan X, Muntner P, et al. Prevalence, awareness, treatment, and control of hypertension in China. Hypertension. 2002:40(6):920-7.

27. Tong SF, Low WY, Ng CJ. Profile of men's health in Malaysia: problems and challenges. Asian J Androl. 2011;13(4):526-33.

28. Tong SF, Low WY, Ismail SB, Trevena L, Willcock S. Physician's intention to initiate health check-up discussions with men: a qualitative study. Fam Pract. 2011;28(3):307-16.

29. Triantafyllou A, Douma S, Petidis K, Doumas M, Panagopoulou E, Pyrpasopoulou A, et al. Prevalence, awareness, treatment and control of hypertension in an elderly population in Greece. Rural Remote Health. 2010:10(2):1225.

30. Saeed AA, Al-Hamdan NA, Bahnassy AA, Abdalla AM, Abbas MAF, Abuzaid LZ. Prevalence, awareness, treatment, and control of hypertension among Saudi adult population: a national survey. Int J Hypertens. 2011;2011:174135.

31. Ha DA, Goldberg RJ, Allison JJ, Chu TH, Nguyen HL. Prevalence, awareness, treatment, and control of high blood pressure: a population-based survey in Thai Nguyen, Vietnam. PLoS One. 2013:8(6):e66792.

32. Pires JE, Sebastião YV, Langa AJ, Nery SV. Hypertension in Northern Angola: prevalence, associated factors, awareness, treatment and control. BMC Public Health. 2013;13:90 
33. Halimi J-M, Giraudeau B, Vol S, Cacès E, Nivet H, Tichet J. The risk of hypertension in men: direct and indirect effects of chronic smoking. J Hypertens. 2002;20(2):187-93.

34. Dochi M, Sakata K, Oishi M, Tanaka K, Kobayashi E, Suwazono Y. Smoking as an independent risk factor for hypertension: a 14-year longitudinal study in male Japanese workers. Tohoku J Exp Med. 2009;217(1):37-43.

35. Doll S, Paccaud F, Bovet P, Burnier M, Wietlisbach V. Body mass index, abdominal adiposity and blood pressure: consistency of their association across developing and developed countries. Int J Obes Relat Metab Disord. 2002;26(1):48-57.

36. Chan JCN, Malik V, Jia WW, Kadowaki T, Yajnik CSC, Yoon K-HK-H, et al. Diabetes in Asia: epidemiology, risk factors, and pathophysiology. JAMA. 2009;301(20):2129-40.

37. Al-naggar RA, Al-dubai SAR, Hamoud T, Chen R, Al-jashamy K. Prevalence and associated factors of smoking among Malaysian university students. Asian Pacific J Cancer Prev. 2011;12:619-24.

38. Noor Ml. The nutrition and health transition in Malaysia. Public Health Nutr. 2002;5(1a):191-5

39. World Health Organization. Global health risks: mortality and burden of disease attributable to selected major risks. Geneva: World Health Organization. 2009.

40. Health Technology Assessment Section, Medical Development Division Ministry of Health, Malaysia. Clinical Practice Guideline on the Management of Hypertension 3rd edition. Putrajaya: Ministry of Health, Malaysia; 2008.

41. Chow CK, Teo KK, Rangarajan S, Islam S, Gupta R, Avezum A, et al. Prevalence, awareness, treatment, and control of hypertension in rural and urban communities in high-, middle-, and low-income countries. JAMA. 2013;310(9):959-68.

\section{Submit your next manuscript to BioMed Central and we will help you at every step:}

- We accept pre-submission inquiries

- Our selector tool helps you to find the most relevant journal

- We provide round the clock customer support

- Convenient online submission

- Thorough peer review

- Inclusion in PubMed and all major indexing services

- Maximum visibility for your research

Submit your manuscript at www.biomedcentral.com/submit
Biomed Central 